\title{
Brucella Myocarditis: A Rare and Life-Threatening Cardiac Complication of Brucellosis
}

\author{
Leila Abid ${ }^{1}$, Zied Frikha ${ }^{1}, \mathrm{~S}$ Kallel ${ }^{3}$, Zayeni Chokri ${ }^{2}$, Benyaakoub Ismahen ${ }^{2}$, Bahloul Amin ${ }^{1}$, \\ Rania Hammami ${ }^{1}$, Dorra Abid ${ }^{1}$, Malek Akrout ${ }^{1}$, Mourad Hentati ${ }^{1}$ and Samir Kammoun ${ }^{1}$
}

\begin{abstract}
This case report represents the difficulties in diagnosing brucellosis, which is an enigma with unusual cardiovascular complications. A 32-year-old Caucasian man with acute chest pain was examined at Sfax Hedi Chaker's Hospital. He had a night fever, although his cardiac examination was normal. Further laboratory analyses showed an elevated C-reactive protein of $20.8 \mathrm{mg} / \mathrm{dL}$ and troponine I of $1.469 \mathrm{IU} / \mathrm{L}$. A cardiac MRI using delayed enhancement was then performed. The T2-weighted short-axis showed a subepicardial delaying enhancement of infero-lateral and the basal walls of the left ventricle. Accordingly, a diagnosis of Brucellarelated myocarditis was made.
\end{abstract}

Key words: brucellosis, myocarditis, cardiac magnetic resonance imaging

(Intern Med 51: 901-904, 2012)

(DOI: 10.2169/internalmedicine.51.6379)

\section{Introduction}

As brucellosis remains a worldwide anthropozoonotic infection, cardiac complications are unusual. According to numerous cardiology publications, such complications occur in $1.5 \%$ of patients (1). The highly frequent cardiovascular complication is endocarditis. In this respect, isolated Brucella myocarditis is a highly rare complication of brucellosis, particularly in the absence of concomitant endocarditis.

\section{Case Report}

A 32-year-old Caucasian man with an acute chest pain presented to the hospital, with a night fever. He did not have ischemic heart disease. His only risk factor was smoking. No recent flu-like syndrome was detected.

The physical examination of the Caucasian man's body showed a blood pressure of 140/75 $\mathrm{mmHg}$ and a heart rate of 100 beats/minute. The first and the second heart-beating sounds were steady. They were without any audible murmurs, rubs or gallops. Similarly, the pulmonary auscultation, the osteoarticular and the abdominal examination were nor- mal. In addition, the physical examination showed a temperature oscillating between $38^{\circ} \mathrm{C}$ and $39^{\circ} \mathrm{C}$. Electrocardiography revealed a sinus rhythm without any noticeable abnormalities. The chest $\mathrm{x}$-ray showed no sign of trouble. Furthermore, a set of laboratory investigations' results indicated an elevated C-reactive protein level of $20.8 \mathrm{mg} / \mathrm{dL}$ and a troponin I of $1.469 \mathrm{IU} / \mathrm{L}$. The hemogram was normal as well as the hepatic enzymes. The transthoracic echocardiography Doppler showed a normal biventricular chamber size with a left ventricular ejection fraction of $65 \%$. Neither regional wall motion abnormalities norpericardial effusion was reported. The patient underwent coronary angiography which showed coronary arteries of normal distribution without significant stenosis. Due to an infectious agent, the diagnosis of myocarditis was suspected along with the history of chest pain associated with a fever and a positive troponin test. Accordingly, a cardiac MRI using delayed enhancement was performed. The T1-short-weighing axis revealed a subepicardial delayed enhancement of infero-lateral and basal walls of the left ventricle which is suggestive of the diagnosis of myocarditis (Fig. 1-3). Serological test of Influenza A and $\mathrm{B}$, parvovirus, EBV, CMV, ECHO virus, coxsackie virus, HSV, VSV, ade adenovirus, Coxiella burnetii, Chlamydia,

${ }^{1}$ Cardiology Department, Hedi Chaker Hospital, Tunisia, ${ }^{2}$ Radiology Department, Charles Nicolle Hospital, Tunisia and ${ }^{3}$ Department of Anesthesia and Intensive Care, Habib Bourguiba Hospital, Tunisia

Received for publication September 7, 2011; Accepted for publication January 5, 2012

Correspondence to Dr. Leila Abid, leilaabidt@yahoo.fr 


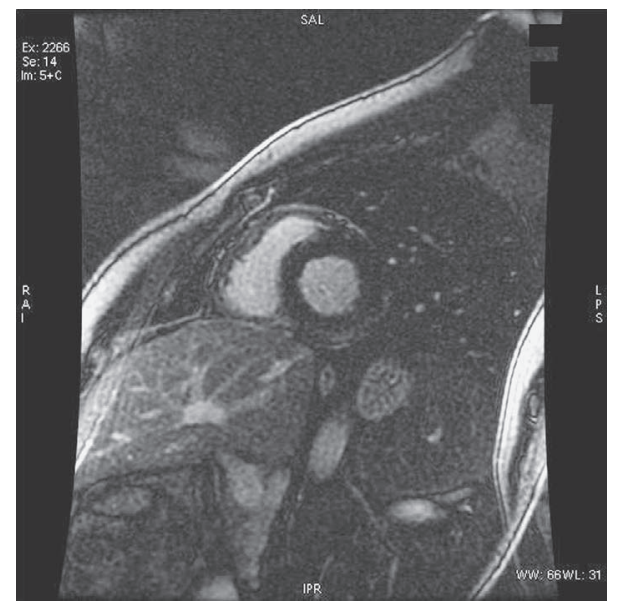

Figure 1. Delayed enhancement in T1 sequence after gadolinium injection in parasagittal view.

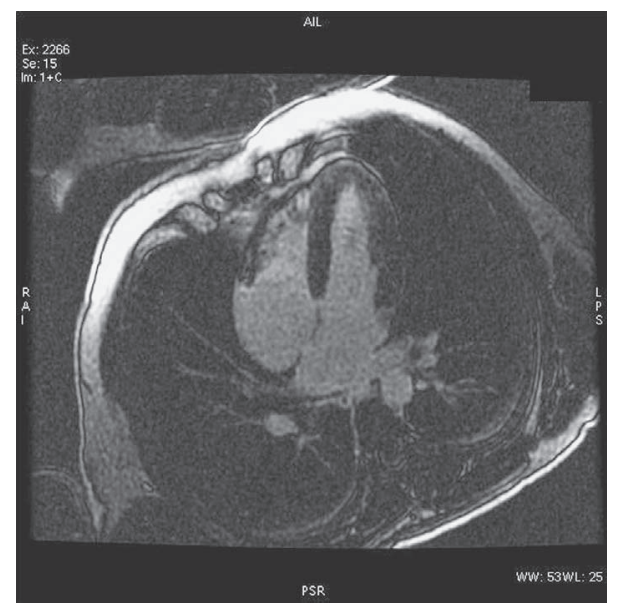

Figure 2. Delayed enhancement in T1 sequence after gadolinium injection in transversal view.

Leptospira and Mycoplasma pneumonia, were proved negative. The treatment of this Caucasian man was initiated with analgesic drugs. Three days later, the patient showed a highgrade fever $\left(39^{\circ} \mathrm{C}\right)$. Additional extensive laboratory blood tests, blood and urine cultures were performed. The Brucella melitensis was isolated from consecutive blood cultures. Two out of eight cultures were proven to be positive and so were the anti-Brucella Coombs- particularly at a rate of $1 /$ 320. Accordingly, a diagnosis of Brucella-related myocarditis was made. There were no clinical signs or laboratory results which suggested the presence of osteoarticular complications, splenicdisease, hepatits or epididymoorchitis. A specific treatment with oral rifampicin of $900 \mathrm{mg}$ and doxycydine of $200 \mathrm{mg}$ along with intramuscular streptomycin of 1 $\mathrm{g}$ once a day per each was immediately carried on. After five days of the treatment, symptoms including fever were regressed rapidly. No signs of heart failure or arrhythmias on serial ECG during the hospital stay were noted. Further, all of the laboratory tests returned to the normal level. The streptomycin therapy was interrupted two weeks after the

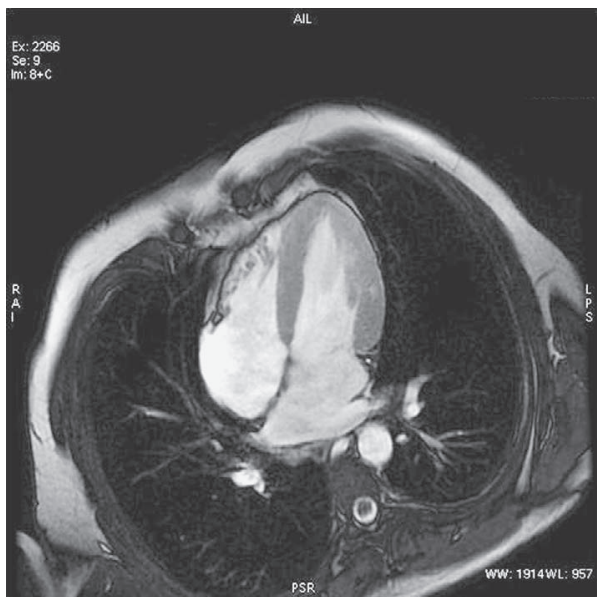

Figure 3. Enhancement in cine fiesta sequence after gadolinium injection.

treatment initiation. The use of the doxycyline and rimpicin were maintained for twelve weeks. The three month clinical and laboratory follow-up showed no sign of relapse. The echocardiographic study revealed a state of complete normality.

\section{Discussion}

Brucellosis is an anthropozoonotic infection with an intense polymorphism. It is largely distributed all over the world. Its prevalence, as a disease, is very high in the Mediterranean countries (2). The transmission of the brucellosis to human-beings is the result of different types of contacts. It may occur through breaks in the skin, particularly with tissues, blood, urine, vaginal discharges, aborted fetuses and especially placentas, and by eating raw milk and unpasteurized dairy products from infected animals. Airborne infection can occur in laboratories and abattoirs (2). Every organ and system of the human body can be affected in brucellosis. Fever is invariable. Physical examination is generally non-specific. Brucella infection has a wide range of clinical complications. The osteoarticular disease, complications of the reproductive system and hepatitis are the most common complications of brucellosis (2). Cardiovascular complications of brucellosis such as endocarditis, myocarditis and pericarditis are rare. However, endocarditis is the most common cardiovascular involvement of the disease. It remains largely the principal cause of mortality in the course of brucellosis. It usually involves the aortic valve and typically requires immediate surgical valve replacement. No good response to medical therapy has been observed. There is poor prognosis without surgery (3). A few case reports have been published in the literature illustrating different forms of Brucella endocarditis' presentation (4-6). In the absence of concomitant Brucella-related endocarditis, development of myocarditis is extremely rare. According to Colmenero et al., only $1.54 \%$ of 530 brucellosis cases had cardiac involvement- with only one patient having myocarditis 
$(0.2 \%)$ (1). Indeed, when we searched in the MEDLINE database for articles published between 1966 and 2011 using the words 'myocarditis' and 'brucellosis', we identified only 11 reports in the English language literature of patients with brucellosis including 13 patients with appropriate information for analysis on brucellosis-related myocarditis in the absence of concomitant endocarditis (5, 7-18).

The mechanism of cardiac damage is not clear. Nevertheless, it can be explained by the direct effect of the microorganism or local deposit of immune complexes (4). The absolute diagnosis of brucellosis requires the isolation of the bacterium from blood or tissue samples. The sensitivity of the blood culture varies. The percentage of cases with positive cultures ranges from 15 to $70 \%$ (2). The diagnosis of Brucella myocarditis is based on the demographic and epidemiologic characteristics of the disease. The presence of symptoms results from serological tests as well as the isolation of the microorganism by blood cultures. It also causes the exclusion of other possible causes of myocarditis. Heart biopsy does not only remain the technique of choice for supporting a definite diagnosis but it may also be of a great help to explain the mechanism of cardiac damage in brucellosis. However, such interventional investigations are not easily implemented in routine clinical practice and add no additional information when a safe diagnosis has already been made by other means.

The gold standard for the diagnosis of brucellosis remains the isolation of Brucella spp. bacteria from samples. However, PCR-based methods that identify nucleic acid fragments from the bacteria are more useful and practical. Most of the new methods for Brucella spp. identification and typing are still being developed and still await validation for use with clinical samples. This is especially true for PCR tests targeting new species of Brucella spp. from marine mammals. Most of these PCR-based methods were developed using Brucella spp. DNA prepared directly from cultured bacteria or extracted from the culture. The sensitivity and specificity of most PCR-based methods are not well established and their real value for use with clinical samples and hence diagnosis has not been validated. There is still a great deal of work required for verification, validation, establishment of standard positive and negative controls, internal and inhibition control, reagents, quality assurance, and contamination before any of these methods may be used in routine laboratory testing for brucellosis (19).

There is a general need for combined antibiotic therapy to treat brucellosis. The guidelines discuss two regimens; they both use doxycycline for a period of six weeks. They may be in combination with either streptomycin from two to three weeks or rifampin for six weeks. The second regimen is more recommended. In the presence of endocarditis, triple antibiotic therapy is advised using doxycycline associated with rifampin for a period of three months in combination with streptomycin from to three weeks. We treated the present patient with triple antibiotic therapy, although the endocarditis has not been found, since it is believed that myo- carditis is considered as a dangerous complication of brucellosis which is associated with a worse prognosis. In addition, what remains as a hindrance is that, there is lack of evidence-based data from large studies on the treatment of this cardiovascular complication in the absence of concomitant endocarditis. Efe et al. show that the patients with Brucella myocarditis usually respond well to antibiotic therapy (17).

\section{Conclusion}

Cardiovascular complications of brucellosis are very rare. The present case illustrates that in endemic areas, Brucella should be considered as a potentially causative agent of myocaditits.

The authors state that they have no Conflict of Interest (COI).

\section{References}

1. Colmenero JD, Reguera JM, Martos F, et al. Complications associated with Brucella mellitensis infection: a study of 530 cases. Medicine 75: 195-210, 1996.

2. Pappas G, Akritidis N, Bosilkovski M, Tsianos E. Brucellosis. N Engl J Med 352: 2325-2336, 2005.

3. Kula S, Erer D, Buyukates M, Tunaoglu FS, Olgunturk R, Ozdogan EM. Brucella endocarditis: case report and review of the literature. J Heart Valve Dis 10: 486-488, 2001.

4. Yildiz A, Tufekcioglu O, Aras D, Ozeke O, Celenk MK, Sasmaz A. Myocardial noncompaction presenting with Brucella endocarditis. Int J Cardiol 131: e87-e89, 2009.

5. Koumallos N, Paschalis A, Antoniades C, et al. Valve replacement for Brucella endocarditis: two case reports. Int J Cardiol 127: e83e85, 2008.

6. Amirghofran AA, Karimi A, Emaminia A, Sharifkazemi MB, Salaminia S. Brucellosis relapse causing prosthetic valve endocarditis and aortic root infective pseudoaneurysm. Ann Thorac Surg 92: e77-e79, 2011.

7. Buczyńska-Hencner S. 3 Cases of myocarditis in the course of brucellosis. Pol Tyg Lek 21: 761-763, 1966 (in Polish).

8. Gatselis NK, Makaritsis KP, Gabranis I, Stefos A, Karanikas K, Dalekos GN. Unusual cardiovascular complications of brucellosis presenting in two men: two case reports and a review of the literature. J Med Case Reports 5: 22, 2011.

9. Elkiran O, Kocak G, Karakurt C, Kuzucu C. Brucella myocarditis in a 3-month-old: probable transplacental transmission. Ann Trop Paediatr 30: 225-228, 2010.

10. Pandit VR, Seshadri S, Valsalan R, Bahuleyan S, Vandana KE, Kori P. Acute brucellosis complicated by fatal myocarditis. Int $\mathbf{J}$ Infect Dis 14: e358-e360, 2010.

11. Khorvash F, Keshteli AH, Behjati M, Salehi M, Emami Naeini A. An unusual presentation of brucellosis, involving multiple organ systems, with low agglutinating titers: a case report. J Med Case Reports 1: 53, 2007.

12. García de Lucas MD, Castillo Domínguez JC, Martínez González MS. Brucella myopericarditis. Rev Esp Cardiol 57: 709, 2004.

13. Villaverde M, Gurini L, González A, Cohen R. Febrile syndrome: myocarditis and brucellosis. Medicina (B Aires) 55: 145-146, 1995 (in Spanish).

14. Marcos Sánchez F, Vázquez García $A$, Juárez Ucelay F, López Onega P, Durán Pérez-Navarro A. Myocardial and pericardial symptoms as a presentation of brucellosis. An Med Interna 8: 100- 
101, 1991 (in Spanish).

15. Jubber AS, Gunawardana DR, Lulu AR. Acute pulmonary edema in Brucella myocarditis and interstitial pneumonitis. Chest 97: 1008-1009, 1990.

16. D'Agrosa MC, Lusson JR, Beytout J, et al. Brucella endocarditis caused by reinfection of an aortic Starr valve. Apropos of a case with a favorable development after valvular replacement. Arch Mal Coeur Vaiss 81: 1403-1407, 1988 (in French).
17. Efe C, Can T, Ince M, Tunca H, Yıldız F, Sennaroglu E. A rare complication of Brucella infection: myocarditis and heart failure. Intern Med 48: 1773-1774, 2009.

18. Ugartemendia MC, Curós-Abadal A, Pujol-Rakosnik M, PujadasCapmany R, Escrivá-Montserrat E, Jané-Pesquer J. Brucella mellitensis pericarditis. Am Heart J 109: 1108, 1985.

19. Yu WL, Nielsen K. Review of detection of Brucella spp. by polymerase chain reaction. Croat Med J 51: 306-313, 2010.

(C) 2012 The Japanese Society of Internal Medicine http://www.naika.or.jp/imindex.html 